\section{A Modified Quick's One-stage Test for the Control of Out-patients on Anticoagulant Therapy}

\author{
B. A. THOMPSON \\ From Group 9 Laboratory, Watford
}

(RECEIVED FOR PUBLICATION NOVEMBER 5, 1959)

In Quick's one-stage test, stage 1 is probably "short-circuited," tissue thromboplastin taking over the function of blood thromboplastin. As a consequence the modified test consists simply of performing the test on fresh whole blood instead of on plasma. The advantage is particularly applicable to outpatients, as the prothrombin time can be estimated straight away and the follow-up dose of the anticoagulant drug prescribed there and then. In a controlled series of 200 tests run in parallel with the standard Quick's method, the incidence of variation of more than two seconds is about $1.2 \%$.

\section{Method}

It is essential to have a $37^{\circ} \mathrm{C}$. water-bath close at hand, so that the venepuncture specimen does not lose too much heat. A small portable electric waterbath $\left(37^{\circ} \mathrm{C}\right.$.) is ideal for this purpose (Fig. 1).

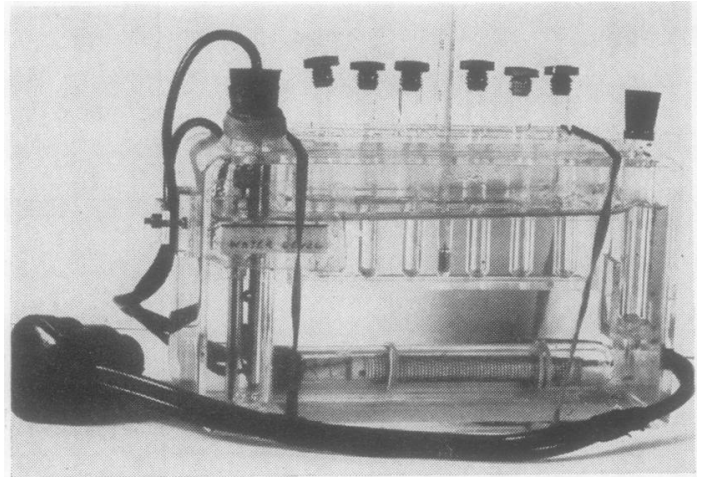

Approximately $0.5 \mathrm{ml}$. of blood is taken from a vein, and, without delay and with the needle still in situ, $0.2 \mathrm{ml}$. of the specimen is delivered into each of two $3 \times \frac{3}{8}$ in. tubes (pre-heated). The water-bath is fitted with a $0.2 \mathrm{ml}$. line for convenience. At least a minute is then allowed for the specimen to reach $37^{\circ} \mathrm{C}$., and $0.2 \mathrm{ml}$. of brain thromboplastin (in a pre-heated tube) is added to the first tube, and the time determined for clotting. The end-point is easier to determine if the tubes are plugged and then gently rocked over an opaque light source. When a clot forms and the specimen ceases to move is the end-point. The test is repeated on the second tube, and the average of the two readings taken. This time is the prothrombin time of the sample.

It is advisable, in colder weather, to use pre-heated $\left(37^{\circ}\right.$ C.) syringes and needles to take the blood specimen.

\section{A Manometric Micro-apparatus for Estimating Oxygen}

\section{F. RAPPAPORT,* F. EICHHORN, AND M. NUTMAN}

From Beilinson Hospital, Petah Tiqwa, and the Weizmann Institute of Science, Rehovot (Israel)

(RECEIVED FOR PUBLICATION AUGUST 27, 1959)

In previous communications (Rappaport, Eichhorn, and Nutman, 1956a and b) an apparatus for manometric determination of $\mathrm{CO}_{2}$ in $0.1 \mathrm{ml}$. and $0.05 \mathrm{ml}$. of plasma was described. The problem of examining oxygen in the same apparatus was still unsolved, but now a method for oxygen determination in $0.1 \mathrm{ml}$. blood samples using the same apparatus has been devised.

Certain precautions must be observed in constructing the apparatus (Fig. 1). Stopcock A should have a capillary bore not more than $1 \mathrm{~mm}$. This is important when introducing sodium hydroxide for $\mathrm{CO}_{2}$ absorption, so that $\mathrm{NaOH}$ enters easily without mixing with hydrargyrum, which is used as a seal immediately afterwards. If the bore is wider, the remains of $\mathrm{NaOH}$, together with the mercury inside, hinder a constant reading as $\mathrm{NaOH}$ continues to flow inside the chamber. The neck of cup $M$ should also be exactly formed. It should be short enough to allow the micro Oswald pipette to touch the opening of the stopcock when introducing the blood into the extraction chamber and also facilitate the sealing with $\mathrm{Hg}$. Each drop of $\mathrm{Hg}$ should fall directly on the bottom of the neck, without air or fluid bubbles. The jacket of the chamber (Fig. 2) should be attached in such a way that the $0.1 \mathrm{ml}$. mark of the reaction chamber should be easily legible.

The micro Oswald pipette should preferably be made out of a part of a $0.2 \mathrm{ml}$. pipette graduated in $0.001 \mathrm{ml}$. so that any quantity of blood introduced into the chamber can be easily calculated. For example, if $0.105 \mathrm{ml}$. blood is introduced by mistake, the calculation can easily be corrected and the examination need not be repeated.

\section{Reagents}

(1) Extraction Solution (Modified) (Rappaport and Köck-Molnar, 1934).
A. 125 g. urea
2 g. saponin alb. Merck
$1.5 \mathrm{ml}$. octyi alcohol
$3 \mathrm{ml}$. concentrated lactic acid
$125 \mathrm{ml}$. distilled water
B. $28 \%$ potassium ferricyanide kept on ice

* The work was completed before Professor Rappaport's illness and subsequent death on July 17, 1959. 


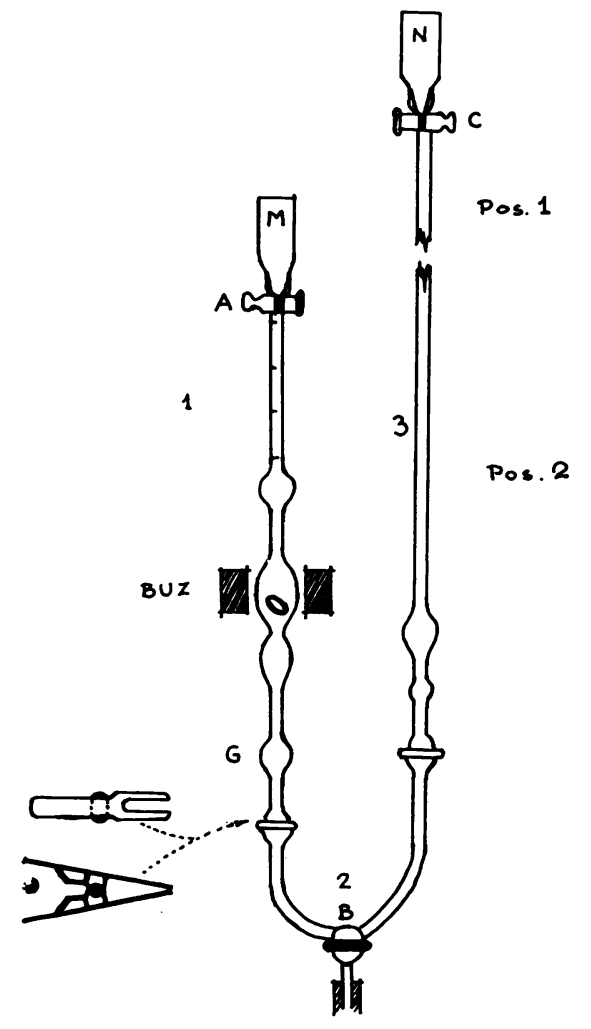

FIG. 1

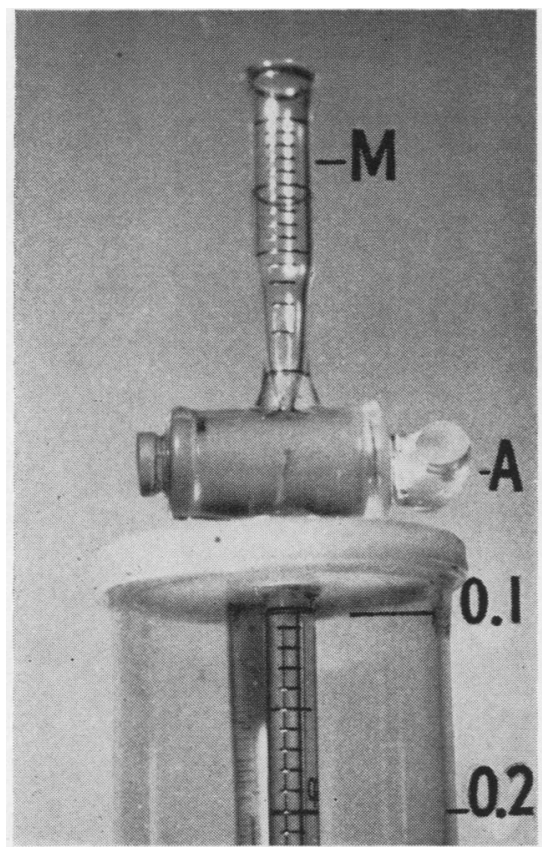

FIG. 2
Mix $2 \mathrm{ml}$. of $\mathrm{A}$ and $0.5 \mathrm{ml}$. of $\mathrm{B}$ just before use. In this solution the octyl alcohol is dissolved homogenously and does, not form an upper layer. With its higher urea content, it prevents the coagulation of proteins and keeps the apparatus clean. It is advisable to use this solution also in the macro Van Slyke apparatus (Rappaport and Köck-Molnar, 1934). Because of the high specific gravity of this solution, the blood introduced into the chamber should run in directly, otherwise it will be dispersed and flood into the extraction solution in the cup. If the construction of the cup $\mathrm{M}$ has not been entirely satisfactory the following solution of a lighter specific gravity must be used.

Alternative Extraction Solution (Van Slyke and Neill, 1924 ; Barcroft, 1914).

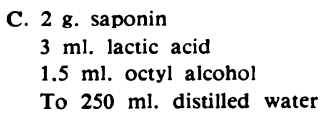

Mix $2 \mathrm{ml}$. of $\mathrm{C}$ with $0.5 \mathrm{ml}$. of $\mathrm{B}$ just before use. Urea is omitted and therefore the beneficial influence of hindering protein precipitation is missing.

The apparatus must therefore be cleaned after each examination with solution 4 . The ferricyanide (B above) if kept separately in the refrigerator is stable for a long time.

(2) $2 \mathrm{~N} \mathrm{NaOH}$.-This is made gas free, preferably in a macro Van Slyke apparatus, and kept under paraffin oil in a calcium chloride tube reservoir as described by Van Slyke. The end of this tube should be equipped with a polyethylene tube (Rappaport and Eichhorn, 1955) and $0.1 \mathrm{ml}$. of the $\mathrm{NaOH}$ solution should give a strong alkaline reaction with phenophthalein when $0.3 \mathrm{ml}$. of the extraction solution is added.

The apparatus is calibrated as described for $\mathrm{CO}_{2}$ estimation (Rappaport et al., 1956b). An apparatus which has been calibrated for $\mathrm{CO}_{2}$ can be used for oxygen without any further preparation. The micro apparatus built by Gallenkamp is calibrated in such a way that the 0.1 and $0.2 \mathrm{ml}$. marks correspond exactly to these amounts. Apparatus built in the laboratory should be carefully calibrated based on examinations in a macro Van Slyke apparatus.

\section{Procedure}

(1) Wash the apparatus with about $0.5 \mathrm{ml}$. octyl alcohol to free it from all fat particles, otherwise the introduction of $\mathrm{NaOH}$ is difficult. This is done once before each series of examinations.

(2) Introduce about $1 \mathrm{ml}$. of extraction solution and free from gas by shaking for two minutes.

(3) Expel gas and raise the fluid into the cup till a small quantity of mercury appears. Introduce $0.1 \mathrm{ml}$. of blood with a micro Oswald pipette tipped with polyethylene (Rappaport and Eichhorn, 1955) and follow it with the extraction fluid till mark $0.4 \mathrm{ml}$. is reached. (The levelling bulb should be in position 2 , as at this position the fluid can 
enter the reaction chamber capillary only down to the $0.4 \mathrm{ml}$. mark.) Seal with mercury, fill the bore of stopcock A with mercury and wash cup $M$ with distilled water. Lower the mercury inside just below the reaction chamber proper (E), where the buzzer stirrer is enclosed, and shake for two minutes (the mercury should not be touched by the stirrer so that it remains clean). Raise the fluid slowly till mark $0.2 \mathrm{ml}$. and read p1. Then raise the fluid to the maximum (levelling bulb in position 2 parallel to 0.4 $\mathrm{ml}$. mark) and introduce 0.1 $\mathrm{ml}$. of $2 \mathrm{~N} \mathrm{NaOH}$ very carefully, seal with mercury, including the boring of stopcock $A$, and wash the cup with distilled water. Read the pressure on the manometer when the fluid meniscus is on the $0.2 \mathrm{ml}$. mark (p2). Read again on the $0.1 \mathrm{ml}$. mark (p3). Expel air and $0.1 \mathrm{ml}$. fluid. Seal with mercury and read $\mathrm{p} 4$ on the $0.2 \mathrm{ml}$. and $\mathrm{p} 5$ on the $0.1 \mathrm{ml}$. mark.

\section{Calculation}

This is done according to the table of Van Slyke and Neill (1924). For $\mathrm{CO}_{2}$ content, p1-p2 is multiplied by the factor found under $\mathrm{CO}_{2}$ content, namely, volume $=1 \mathrm{ml}$., $\mathrm{a}=2 \mathrm{ml}$.

For oxygen content, p2-p4 is multiplied by the factor found in the same table under oxygen content, namely: volume $=1 \mathrm{ml} ., \mathrm{a}=2 \mathrm{ml}$.

The result gives the $\mathrm{CO}_{2}$ and oxygen contents respectively in volume per cent.

For example, temperature $=20^{\circ} \mathrm{C}$, factor for $\mathrm{CO}_{2}=0.2655$, and factor for $\mathrm{O}_{2}=0.2450$. p3-p5 multiplied by the factor and divided by 2 give the same oxygen content (the reading is only higher, which is preferable for small quantities).

If the $\mathrm{CO}_{2}$ content is of no interest, as in heart catheterization where oxygen and oxygen capacity only are important, the reading of $p 1$ can be omitted. For this purpose, attempts were made to extract the oxygen directly in an alkaline medium, as in the procedure of Barcroft (1914) and Haldane with their volumetric apparatus, but they failed. Apparently mercury or octyl alcohol interferes with the process and the results were constantly too low.

The results for $\mathrm{CO}_{2}$ and oxygen obtained in the micro apparatus compared favourably with those of the original Van Slyke apparatus.

Fig. 3

To simplify the apparatus further, absolute airtightness was achieved by using simple ball joints with two clamps (Fig. 3), and not as described above with a mercury sealing. When the apparatus has to be cleaned and the ball joints are frozen, they can easily be freed by warming with a hair dryer.

Gallenkamp has constructed a macro apparatus with ball joints; a micro attachment for it was made by removing the extraction chamber and replacing it with a micro one as described above. The combined apparatus gave very satisfactory results.

\section{Summary}

An improved extraction fluid, precautions to be taken in constructing the micro apparatus, and the procedure for the determination of the oxygen content of blood in $0.1 \mathrm{ml}$. samples are described, using the manometric micro apparatus for gas analysis.

It is also possible to use the same micro extraction chamber and attach it to a macro apparatus, provided the same size of ball joints is used for both types of apparatus.

We are grateful to Mrs. Jehudith Shashdy for her assistance in performing the final experiments.

\section{REFERENCES}

Barcroft, J. (1914). The Respiratory Function of the Blood. University Press, Cambridge.

Rappaport, F., and Eichhorn, F. F. (1955). Amer. J. med. Technol. 21, 46.

- - and Nutman, M. (1956a). J. clin. Path., 9, 166. (1956b). Clin. Chim. Acta, 1, 305

Van Slyke, D. D., and Neill, J. M. (1924). Ibid., 61, 561. 